\title{
3D CFD fluid flow and thermal analyses of a new design of plate heat exchanger
}

\author{
Paulina Pianko-Oprych*, Zdzisław Jaworski \\ West Pomeranian University of Technology, Szczecin, Institute of Chemical Engineering and Environmental Protection \\ Processes, Faculty of Chemical Technology and Engineering, al. Piastow 42, 71-065 Szczecin, Poland \\ "Corresponding author: e-mail: paulina.pianko@zut.edu.pl
}

\begin{abstract}
The paper presents a Computational Fluid Dynamics (CFD) numerical study for a new design of a plate heat exchanger with two different flow patterns. The impact of geometric characteristics of the two studied geometries of exchanger plates on the intensification process of heat transfer was considered. The velocity, temperature and pressure distributions along the heat exchanger were examined. The CFD results were validated against experimental data and a good agreement was achieved. The results revealed that geometrical arrangement of the plates strongly influence the fluid flow. An increase in the Reynolds number led to lowering the friction factor value and increasing the pressure drop. The configuration II of the plate heat exchanger resulted in lower outlet hot fluid temperature in comparison with the configuration I, which means improvement of heat transfer.
\end{abstract}

Keywords: CFD analysis, plate heat exchangers, pressure drop, temperature profile.

\section{INTRODUCTION}

Plate heat exchangers have been frequently studied ${ }^{1,2}$ due to their broad application in a wide range of industries including air conditioning and heat pump coils, steam power boilers, home heating convectors as well as wasteheat recovery ${ }^{3}$. Advances affecting the performance of plate heat exchangers were summarized by Abu-Khader ${ }^{4}$. In the review ${ }^{4}$, the selected issues such as thermal and hydrodynamic characteristics, two-phase flows as well as fouling and corrosion were discussed. Main research efforts were made to develop advanced compact plate heat exchangers that can effectively exchange heat between two fluid streams having a low temperature difference.

In order to increase the effectiveness of plate heat exchangers, a multi-pass design of several manifold microchannel segments was proposed by Arie et al. ${ }^{5}$. The short flow path through the microchannels maintain the flow in the developing regime and ensure better heat transfer than in that of fully developed flow as well as reduced pressure drop. To estimate the optimum performance of the heat exchanger, a hybrid computational method was developed based on solution of full 3D Navier-Stokes and energy equations in a microchannel segment of the heat exchanger in combination with 1D momentum and mass balance equations in manifolds. Another solution was presented by Goodarzi and Nouri ${ }^{6}$. They showed that a double pass arrangement cools the channel walls down more symmetrically, in comparison to the simple pass arrangement, with better uniformity in wall temperature distribution. The uniformity index increases by $16.7 \%$ compared to the original heat exchanger. However, power consumption for handling the coolant flow increases in comparison to the original solution. In addition, they noticed that sinusoidal separating plate increased heat transfer performance compared to the flat one. Wavy plates instead of usual flat plate for channels' walls were also recognized as better solution by Kim et al. ${ }^{7}$. A 2D five way fin with corrugation angle $20^{\circ}$ was used as the geometry for simulation and the cross-cut was applied at the third wave. The results showed that the heat performance of optimized cross cut wavy fin was enhanced by a maximum of $23.81 \%$ more than for a typical wavy fin. The pressure drop also increased up to $7.04 \%$ in optimized case. Finned and wavy walls generate secondary flows along the flow direction which increase the local convective heat transfer coefficient.

Taking into account that the convective heat transfer coefficient depends on flow pattern through the channel, the only way for increasing its value is to change the flow pattern within the internal channel space ${ }^{6}$. Therefore, the effect of fluid flow nonuniformity on heat exchanger efficiency is of first order importance and has decisive impact on their efficiency due to maldistribution of interior temperature. According to Yaici et al. ${ }^{8}$ two main types of the flow nonuniformity can be distinguished: gross maldistribution and passage-to-passage maldistribution. The first type is associated with improper heat exchanger entrance configuration, such as poor design of header and distributor configuration. The second type of passage-to-passage flow maldistribution occurs in a highly compact heat exchanger caused by various manufacturing tolerances.

Yaici et al..$^{8}$ studied a variety of inlet air flow distributions on in-line and staggered plate-fin-and-tube heat exchangers in order to estimate their effects on system performance including Reynolds number, Prandtl number, geometrical parameters of the heat exchanger, tube arrangement and different working fluids. Their results indicated that either up to $50 \%$ improvement or deterioration in the Colburn factor and the friction factor were found compared to the baseline case of a heat exchanger with uniform inlet velocity profile. It was confirmed that the tube arrangement plays a critical role in the heat transfer and pressure drop characteristics. In staggered arrangements, there was better flow mixing due to staggered tube layouts and higher heat transfer. In addition, it was shown that the inlet air flow distribution has a significant impact on the fluid flow and heat transfer characteristics and the thermo-hydraulic performance. The pressure drop decreased monotonically along the heat exchanger, however, its value increased with the inlet velocity of the air flowing into the heat exchanger. The authors ${ }^{8}$ concluded that the inlet airflow distribution can be used as a mechanism to enhance the local heat 
rate. A similar study was carried out by Vafajoo et al. ${ }^{9}$ for flue gas-air Chevron type plate heat exchangers. A higher angle of the Chevron type plates resulted in $18 \%$ enhancement in the output air temperature and an increase of $63 \%$ in the gas pressure drop in comparison with the plate heat exchanger.

Most of the research on heat exchangers has been carried out experimentally or analytically due to their complexity. A variety of techniques of enhancing heat transfer in plate heat exchangers was presented by Shah and Sekulic ${ }^{\mathbf{1 0}}$ based on the method of Logarithmic Mean Temperature Difference (LMTD) or the exchanger effectiveness $\varepsilon-$ Number of Transfer Units NTU ( $\varepsilon$-NTU). Using those methods, Wakui and Yokoyama ${ }^{11}$ developed a steady-state model of a shell and tube heat exchanger for performance monitoring based on an online model. With improving capabilities of commercial CFD codes and cost of computing power, numerical investigations of flow maldistribution effects on heat exchanger performance became more common. For example, Tao et al. ${ }^{12}$ simulated a multistage heat exchanger with plain fins and slit fins. The better heat transfer conditions in the slit fin heat exchanger were attributed to better synergy between the velocity and temperature gradients. A detailed analysis of the velocity distribution in a corrugation plate heat exchanger was given by Luan et al. ${ }^{13}$. It was noticed that the longitudinal corrugation in compound corrugation plate was inducing cross mixing of the working fluid and thus enhancing turbulence and also heat transfer between the fluid and the plate. Numerical simulations and experiments showed that the flow resistance of working fluid in the corrugation plate heat exchanger was decreased more than $50 \%$ in comparison to the traditional Chevron type one and hence the problem of flow path blockage can be effectively avoided. More recently, Giurgiu et al. ${ }^{14}$ performed flow analysis through mini channels in plate heat exchangers. The analysed mini channels had the inclination angles from $30^{\circ}$ to $60^{\circ}$. Both the experimental and CFD results showed that the best heat transfer conditions were obtained for the plate heat exchanger with inclination angle of $60^{\circ}$. In addition, it was noticed that the geometry of the plates significantly affects the fluid flows through channels formed between the plates and highlights the performance of thermodynamic characteristics of these devices. The use of manifolding of microchannels for performance enhancement of plate heat exchangers in a counter flow configuration was studied also by Andhare et al. ${ }^{15}$. The heat transfer coefficient obtained in the numerical simulations was found to be approximately $16 \%$ higher than that in the experimental findings. The deviation between numerical and experimental values was explained due to the variability of the microchannels. The heat exchanger was made of nickel, which is quite difficult to machine and it can lead to variability in microchannel dimensions. Another significant observation was that the introduction of the fluid into a developing flow region enhanced the performance of the heat exchanger. The contour plots of the velocity obtained from the numerical study showed higher local flow velocities near the base of the microchannel. This effect was explained by turning of the flow from manifold to microchannel and back to the manifold in a very short flow length.
The need of investigation of the effect of corrugated flat plate heat exchanger with and without baffles on the thermal-hydraulic characteristics, including efficiency of heat transfer and flow resistance in heat exchanger, was recognized by Rios-Iribe et al. ${ }^{\mathbf{1 6}}$. The impact of plates number and distance between plates on the heat transfer and the friction factor were studied over a wide Reynolds number range in the case of non-Newtonian fluids flowing through the plate heat exchangers. It was found that for all investigated Reynolds numbers in the heat exchanger with two plates, the CFD results correctly fitted an empirical correlation of the friction factor. The variation of heat transfer was presented as a function of the pumping power. It was found that at high flow rate, an increase in the number of used plates lowered the ratio between the heat transfer and the pumping power. Other aspects were considered by Dvorak and $\mathrm{Vit}^{17}$, who focused on an effect of material thickness on pressure loss and effectiveness of a counter flow plate heat exchanger. The authors demonstrated that the low material thickness, of only $5 \%$ of the plate pitch, was crucial in creating the most effective recuperative air to air heat exchanger with high effectiveness and low pressure loss, while the properties of the material itself were unimportant. The CFD results for effectiveness corresponded well with the measured ones, while the results for pressure loss differed significantly and underestimated the measured pressure drop by $19-75 \%$ in a wide Reynolds number range. The high difference in pressure loss was explained by not taking into account in simulations the plate parameters, such as plate roughness, plate deformation or differences between the shapes of the numerical and real plates of the heat exchangers.

Most of the reviewed papers clearly indicated that non-uniform fluid flow at the inflow to the narrow passage formed between the fins as well as the thermal contact resistance between the fin and tube/plate can strongly influence the heat transfer process inside plate heat exchangers. Thus, in the case of those exchangers, where fluid flow through parallel flat plates is characterized by the formation of large dead flow zones, supporting the reliability of the computation seems to be particularly useful. The CFD codes allow predicting how these undesirable thermal-hydraulic characteristics can be reduced and hence lead to an increase in the pressure drop and the heat transfer. The presented results ${ }^{8,14-17}$ showed that 3D CFD simulations can provide an effective tool for engineering analysis since various design options and a wide variety of physical conditions can be examined without constructing expensive test rigs or large scale prototypes. Thus an optimal design of the plate heat exchanger can be determined at a relatively low cost.

Therefore, the aim of the study was to examine the influence of geometrical parameters of the heat exchanger plates on heat transfer conditions by means of the CFD modelling. With this aim, the plate heat exchangers of two different flow patterns were studied and the CFD results were compared with an existing experimental data for the original geometry of the plate heat exchanger. 


\section{NUMERICAL APPROACH}

The scheme of a plate heat exchanger with two different configurations I and II, for which computations of velocity, pressure and temperature were conducted, is shown in Figure 1. The plate heat exchanger is used for cooling the cathode off gas leaving a developed hybrid power generation system based on Solid Oxide Fuel Cells. To simplify the computational case, the cathode off gas was represented by air flow with the same mass flow rate and temperature values as the cathode off gas in a real system. The cathode off gas was marked as hot flow and it was cooled by air (cold flow). The complete plate heat exchanger was $95 \mathrm{~mm}$ wide, 210 $\mathrm{mm}$ long and $33 \mathrm{~mm}$ thick. The total number of plates was equal to 18 resulting in 9 and 8 channels for cold and hot flows, respectively. The plate fins and walls were made of stainless steel with the thermal conductivity of $k=16.27 \mathrm{~W} / \mathrm{mK}$. The fins of the hot and cold flows in the plate heat exchanger configuration I were J-shaped, while for the configuration II the fins for the hot flow were straight and for the cold fluid flow they were S-shaped. Relevant 3D geometrical models of plate heat exchanger were built in the CFD commercial software ANSYS Workbench.

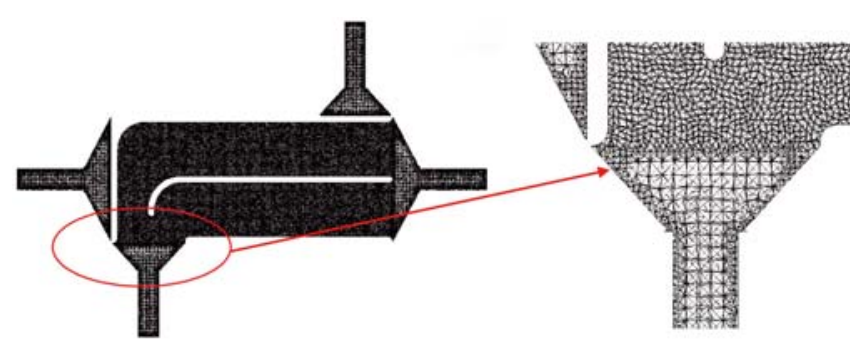

Figure 2. The tetrahedral mesh of the heat exchanger configuration I

the turbulent flows through the plate heat exchanger the RNG $k$-epsilon model was used with standard values of model constants. The behaviour of this model near the wall was corrected by incorporating the standard wall functions. The working fluids were assumed Newtonian, incompressible with piecewise linear temperature profile properties presented in Table 1.

The counter flow of the flowing streams was considered. Thirteen cases for both configurations of the plate heat exchanger were simulated using different boundary conditions. The mass flow rates, $N$, and temperatures, $T$, of the inlet cold and hot streams were set fixed to the values shown in Table 2 . Turbulence intensity was set at

(a) configuration I

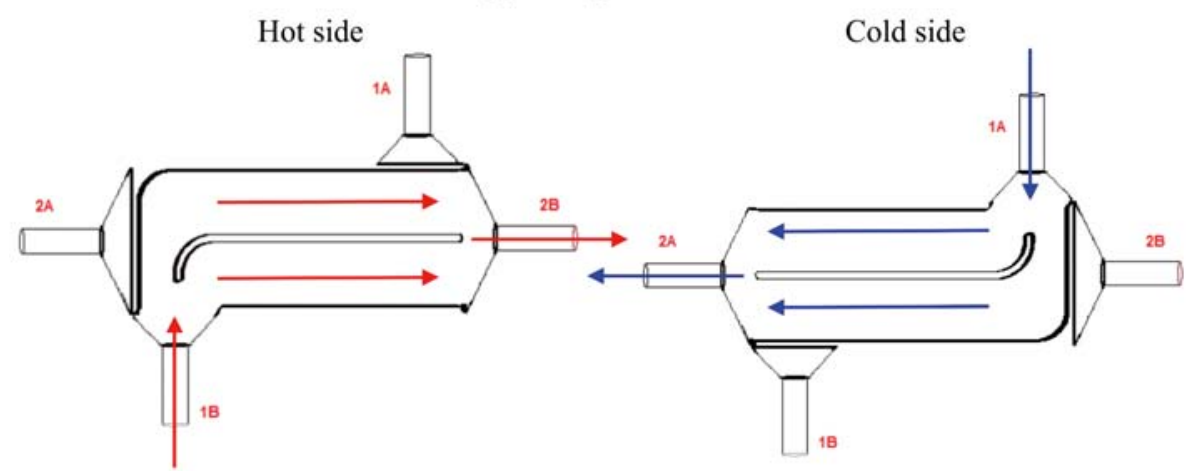

(b) configuration II

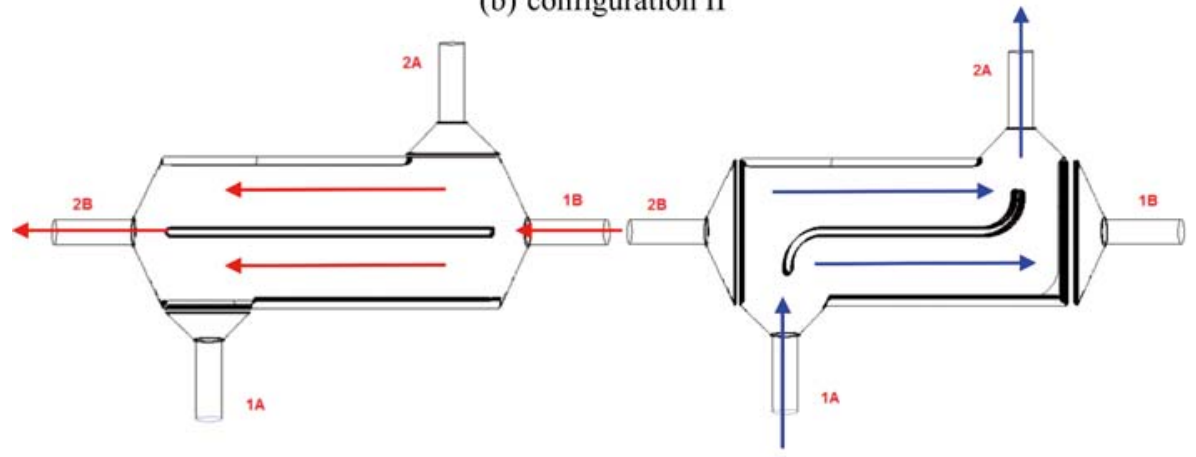

Figure 1. Flow scheme of plate heat exchanger with two different configurations where: $1 \mathrm{~A}$ - inlet manifold for the cold flow, $2 \mathrm{~A}$ - outlet manifold for the cold flow, $1 \mathrm{~B}$ - inlet manifold for the hot flow, $2 \mathrm{~B}$ - outlet manifold for the hot flow

Both configurations of the plate heat exchanger were meshed by using triangular mesh in the grid generator ANSYS Meshing. The number of computational cells was equal to 1.38 and 1.56 million for configurations I and II, respectively. Figure 2 displays samples of numerical mesh for a horizontal plane intersecting a hot section of the heat exchanger at half of its depth.

The following assumptions were considered in the developed approach: the working fluid was air for both cold and hot flows within the turbulent regime. To simulate
$5 \%$ what was acceptable given the sufficient entry length provision. Zero velocity with no slip shear condition was applied to the flow in the boundary layer at walls.

Since the study was assumed for stationary conditions, the Navier-Stokes and energy equations in three dimensional form $^{18}$ were used to solve for the steady state hydrodynamics and thermal fields in the plate heat exchanger. The hot fluid flow was treated as a non-participating media in radiation ${ }^{22}$. The governing equations are presented in Table 3. 
Table 1. Material properties of the working fluid

\begin{tabular}{|l|c|c|c|}
\hline $\begin{array}{l}\text { Temperature } \\
{[\mathrm{K}]}\end{array}$ & $\begin{array}{c}\text { Specific heat capacity } \\
{[\mathrm{J} / \mathrm{kgK}]}\end{array}$ & $\begin{array}{c}\text { Viscosity } \\
{\left[10^{-5} \mathrm{~kg} / \mathrm{ms}\right]}\end{array}$ & Thermal Conductivity $[\mathrm{W} / \mathrm{mK}]$ \\
\hline 400 & 1013.5 & 2.286 & 0.03365 \\
\hline 450 & 1020.6 & 2.485 & 0.03710 \\
\hline 500 & 1029.5 & 2.670 & 0.04041 \\
\hline 550 & 1039.8 & 2.849 & 0.04357 \\
\hline 600 & 1051.1 & 3.017 & 0.04661 \\
\hline 650 & 1062.9 & 3.178 & 0.04954 \\
\hline 700 & 1075.0 & 3.332 & 0.05236 \\
\hline 750 & 1087.0 & 3.482 & 0.05509 \\
\hline 800 & 1098.7 & 3.624 & 0.05774 \\
\hline 850 & 1110.1 & 3.763 & 0.5840 \\
\hline 900 & 1120.9 & 3.897 & 0.5430 \\
\hline 950 & 1131.3 & 4.026 & 0.5043 \\
\hline 1000 & 1141.1 & 4.153 & 0.4706 \\
\hline
\end{tabular}

Table 2. Boundary conditions for the hot and cold fluids in the plate heat exchanger

\begin{tabular}{|l|c|c|c|c|c|c|}
\hline \multirow{2}{*}{ Case } & \multicolumn{2}{|c|}{ Hot fluid } & \multicolumn{2}{c|}{ Cold fluid } \\
\cline { 2 - 7 } & $\begin{array}{r}R e \\
{[-]}\end{array}$ & $T_{\text {inlet-hot }}[\mathrm{K}]$ & $\begin{array}{c}N_{\text {inlet-hot }} \\
{[\mathrm{kg} / \mathrm{s}]}\end{array}$ & $\begin{array}{c}R e \\
{[-]}\end{array}$ & $T_{\text {inlet-cold }}[\mathrm{K}]$ & $N_{\text {inlet-cold }}[\mathrm{kg} / \mathrm{s}]$ \\
\hline 1 & 6053 & 562.8 & 0.002008472 & 6192 & 425.4 & 0.00205616 \\
\hline 2 & 6053 & 754.0 & 0.002008472 & 6115 & 425.8 & 0.00203064 \\
\hline 3 & 6053 & 932.1 & 0.002008472 & 6089 & 435.2 & 0.00202213 \\
\hline 4 & 6084 & 958.1 & 0.002018897 & 6115 & 443.9 & 0.00203064 \\
\hline 5 & 4576 & 943.8 & 0.001518504 & 4563 & 438.2 & 0.00151547 \\
\hline 6 & 3068 & 927.8 & 0.00101811 & 3039 & 428.6 & 0.00100934 \\
\hline 7 & 1466 & 890.2 & 0.000486442 & 1605 & 409.1 & 0.00053298 \\
\hline 8 & 6147 & 659.8 & 0.002039747 & 8420 & 315.3 & 0.00279621 \\
\hline 9 & 3037 & 642.1 & 0.001007685 & 8433 & 315.6 & 0.00280047 \\
\hline 10 & 3005 & 550.0 & 0.00099726 & 1605 & 311.8 & 0.00053298 \\
\hline 11 & 1528 & 536.9 & 0.000507292 & 913 & 309.8 & 0.00030331 \\
\hline 12 & 10105 & 616.8 & 0.003353279 & 6499 & 315.3 & 0.00215823 \\
\hline 13 & 10105 & 989.1 & 0.003353279 & 10034 & 437.6 & 0.00333212 \\
\hline
\end{tabular}

Table 3. The governing equations

\begin{tabular}{|l|l|l|}
\hline Type & Equation & No \\
\hline Mass conservation & $\nabla \cdot(\rho \bar{v})=0$ & (1) \\
\hline Momentum & $\nabla \cdot(\rho \overline{v v})=-\nabla p+\nabla(\bar{\tau})+\rho \bar{g}$ & (2) \\
\hline Energy & $\nabla \cdot\left(\rho C_{p} \bar{v} \bar{T}\right)=\nabla \cdot(\lambda \nabla \bar{T})$ & (3) \\
\hline Turbulent kinetic energy & $\frac{\partial\left(\rho \overline{v_{i}} K\right)}{\partial x_{i}}=\frac{\partial}{\partial x_{i}}\left[\left(\mu+\frac{\mu_{t}}{\sigma_{k}}\right) \frac{\partial K}{\partial x_{i}}\right]-\rho \overline{v_{i}^{\prime}} \bar{v}_{j}^{\prime} \frac{\partial \overline{v_{j}}}{\partial x_{i}}-\rho \varepsilon$ & (4) \\
\hline $\begin{array}{l}\text { Dissipation rate of } \\
\text { turbulent kinetic energy }\end{array}$ & $\frac{\partial\left(\rho \overline{v_{i}} \varepsilon\right)}{\partial x_{i}}=\frac{\partial}{\partial x_{i}}\left[\left(\mu+\frac{\mu_{t}}{\sigma_{\varepsilon}}\right) \frac{\partial \varepsilon}{\partial x_{i}}\right]+C_{1 \varepsilon} \frac{\varepsilon}{K}\left[-\rho \overline{v_{i}^{\prime \prime}} \overline{v_{j}} \frac{\partial \overline{v_{j}}}{\partial x_{i}}\right]+$ & (5) \\
\hline
\end{tabular}

where: $\delta_{k}$ is constant in Equation (4), $\mathrm{C}_{1 \varepsilon}, \mathrm{C}_{2 \varepsilon}, \delta_{\varepsilon}$ are adjustable constants in Equation (5), while ${\underset{=}{\mu}}_{\mu}$ is the constant in Equation $(7)^{\mathbf{1 8}}$. The stress tensor, $\bar{\tau}$, turbulent viscosity, $\mu_{t}$, RNG additional term, $R_{\varepsilon}$, as well as ratio of the mean flow to turbulent time scale are given by Equations (6) - (9), respectively:

Stress tensor: $\stackrel{\bar{\tau}}{\tau}=\mu\left[\nabla \bar{v}+\nabla \bar{v}^{T}-\frac{2}{3} \nabla \bar{v} \bar{I}\right]$

Turbulent viscosity: $\mu_{t}=\rho C_{\mu} \frac{K^{2}}{\varepsilon}$
RNG additional term: $R_{\varepsilon}=\frac{\rho C_{\mu} \eta^{3}\left(1-\eta / \eta_{0}\right)}{1+\beta \eta^{3}} \frac{\varepsilon^{2}}{K}$

Ratio of the mean flow to turbulent time scale: $\eta=S \frac{K}{\varepsilon}$

The RNG k- $\varepsilon$ model delivers a better response to the instantaneously changing flow with the additional term, $R_{\varepsilon}$, in comparison to the standard k- $\varepsilon \operatorname{model}^{23}$.

The modeling was conducted using the commercial CFD code ANSYS Fluent 15.0. The governing equations 
were discretized by the Finite Volume Method, the pressure-velocity coupling was implemented by SIMPLE algorithm, while the convection terms were discretized by Second Order Upwind, and the First Order Upwind scheme was selected for the kinetic energy and its dissipation rate. The first step was to determine the pseudo-laminar flow fields with the turbulence model turned off, then the turbulence model was activated in the computations to simulate the turbulent velocity fields and finally the energy equation was solved. The iterations were carried out as long as the standardized sum of residuals fell below $1 \cdot 10^{-4}$ and the residual plots showed a plateau for at least 100 last iterations.

The CFD model was validated by quantitative comparison to the experimental results obtained from the industrial project partner - sunfire ${ }^{19}$. In addition, the Fanning friction factor, f, was calculated as follows (Eq. $(10))^{20,21}$ :

$$
f=\frac{\Delta P}{L} \cdot \frac{D_{h}}{2 \rho v^{2}}
$$

in which $\Delta P$ is the pressure drop equal to the difference between the inlet and outlet, where $L$ and $D_{h}$ are the length and hydraulic diameter of the channel, respectively.

For fully developed turbulent flows $(2000<\operatorname{Re}<25000)$ the Fanning friction factor for heat exchanger was given in Eq. (11) by ${ }^{13}$ and used for comparison with the simulation results.

$$
f=0.39 \cdot \operatorname{Re}^{-0.19}
$$

\section{RESULTS AND DISCUSSION}

The plots of the friction factor as the function of the Reynolds number in the heat exchanger with the two-plate configurations is shown in Figure 3. For both configurations of the heat exchanger a good agreement can be seen between the calculated friction factor and the experimental values as well as the theoretical relationship (11) over the Reynolds number range of 4500-10106 [-]. However, the friction factor tends to be strongly dependent on the geometrical shape of the heat exchanger. At the inlet area, a constant flow is defined by the geometrical shape of the tubular manifold. Then the flow gets into the main area of the heat exchanger and it is divided into two parts. In addition, plates arrangement in the configuration I for both hot and cold fluid channels cause the flow changes its direction by $90^{\circ}$, inducing secondary flows that produce dead flow zones in the curvature of the channel visible in Figures 4a and 5a at the upper left corners at a lower flow rate $(R e=1528)$. However, at a higher flow rate the flow tends to limit dead flow zones as showed in Figures $4 \mathrm{~b}$ and $5 \mathrm{~b}$ for two cases of Table 2. Clear dead flow areas to occur in the cold fluid zone (Fig. 5b upper part) and it seems that S-shaped plates strengthen this phenomenon independently of the flow rate studied.

In addition, for the second configuration of the plate heat exchanger, the velocity field for the cold fluid zone strongly depends on the geometrical arrangement of the plates and at high Reynolds number the dynamic losses are greater (Fig. 5b) than those observed in the configuration I (Fig. 4b) at the same Reynolds number, $R e=10$ 105. Dead flow zones decrease when the inlet
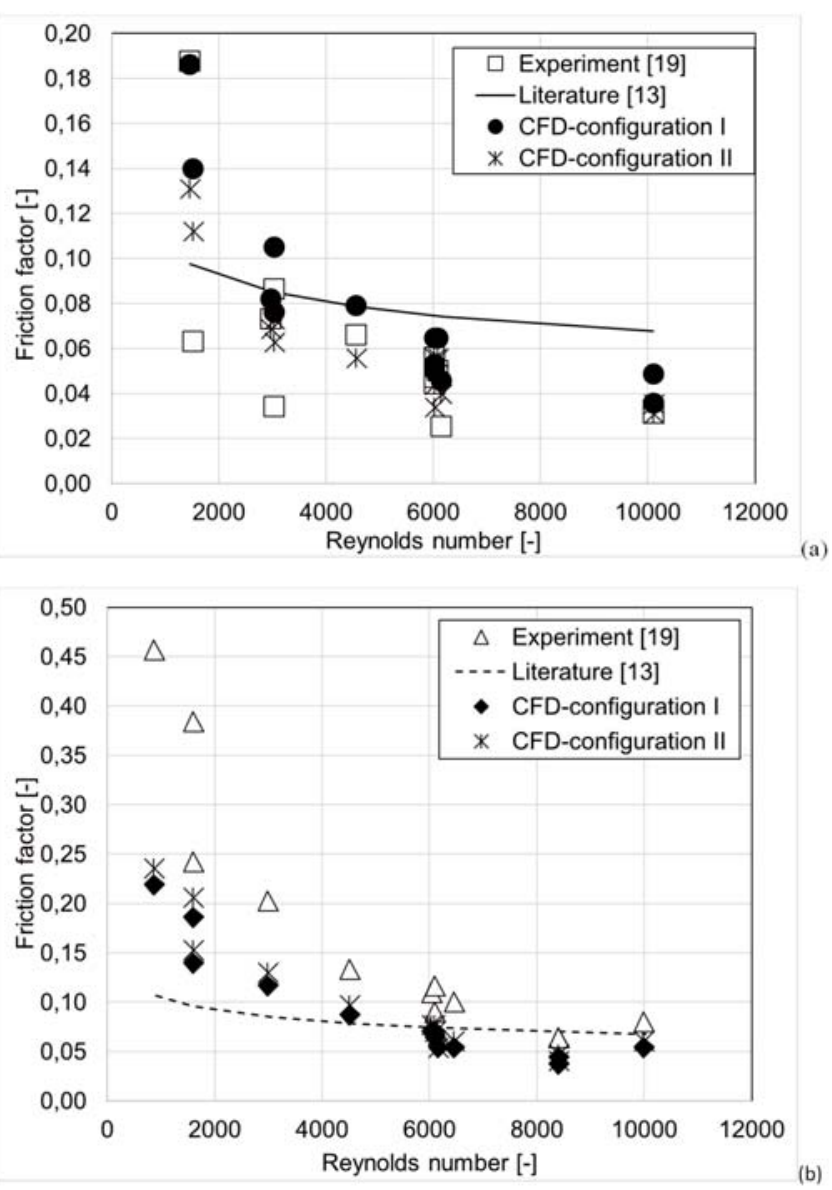

Figure 3. Comparison of the CFD predicted, experimental and literature 13 values of friction factor for both configurations I and II of the plate heat exchanger: (a) hot fluid flow, (b) cold fluid flow

velocity increase due to the fluid inertia inducing the reverse fluid flow in areas between plates and heat exchanger walls.

The accuracy of numerical predictions was evaluated based on the standard deviation between the measurement and model results of pressure drop for each considered case as a function of the plates shape (configurations I and II). Figure 6 presents the impact of the flow regime and heat exchanger configuration on the pressure drop.

A significant deviation of $40 \%$ between the predicted and measured values of pressure drop was noticed at the operating mass flow rates for both hot and cold fluid flows in the plate heat exchanger configuration I. For the configuration II, however, these differences were lower and the mean standard deviations of $12 \%$ and $32 \%$ were noticed for the hot and cold fluid flow, respectively. It should be mentioned that the calculated pressure drop using the CFD model for the hot fluid flow was overestimated, while that for the cold fluid was underestimated in both configurations. Figures 7 and 8 show the contours of local pressure for both fluids: hot and cold and the two heat exchanger configurations.

The pressure decreases monotonically along the heat exchanger in both fluid zones as expected. However, it should be underlined a strong effect of the plates arrangement on the pressure distribution. In the pressure distributions presented in Figures 7 and 8, high pressure spots can be noticed for both fluids resulted from the flow interactions with these vertical plates. The presence of those plates causes fluid fluctuations. Thus, the ve- 

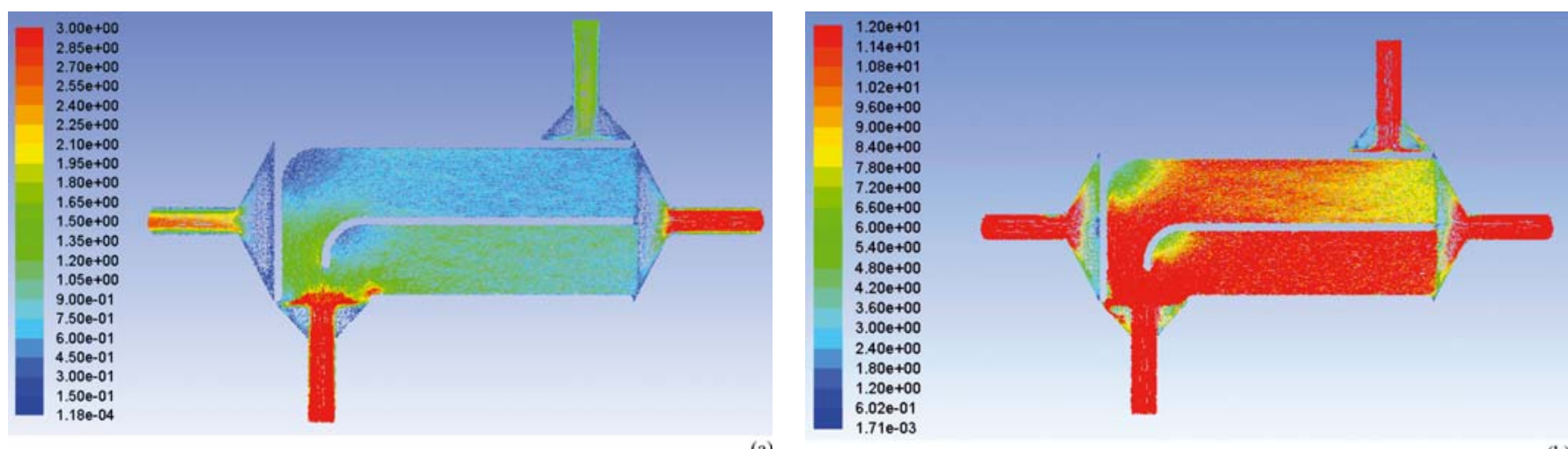

(a)

Figure 4. Velocity vectors distribution $[\mathrm{m} / \mathrm{s}]$ for hot side in the heat exchanger - configuration I: (a) case 11 , (b) case 13
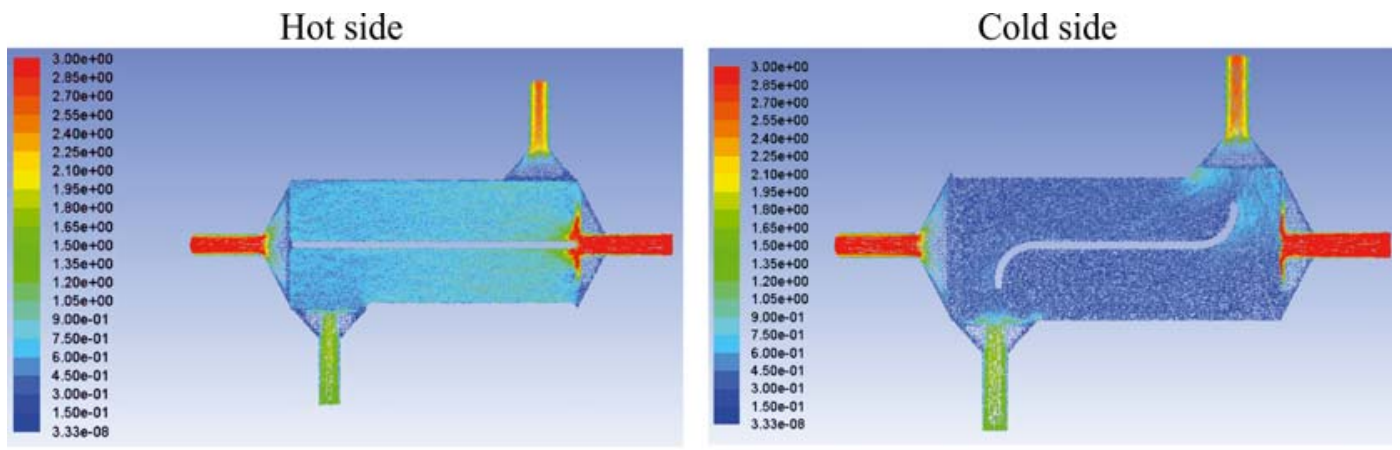

(a)
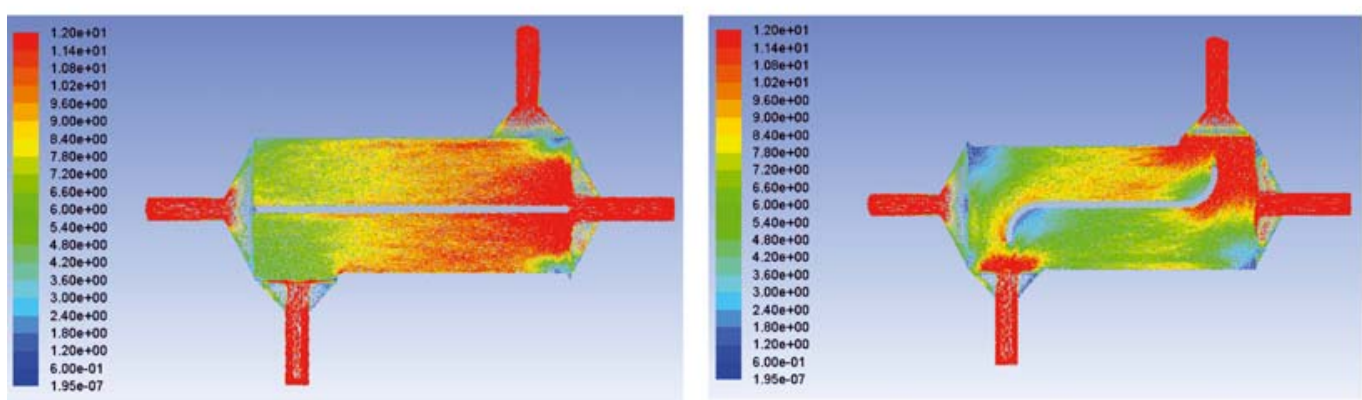

(b)

Figure 5. Velocity vectors distribution $[\mathrm{m} / \mathrm{s}]$ in the heat exchanger - configuration II for hot and cold fluids: (a) case 11 , (b) case 13

locity and pressure distributions have strong impact on heat transfer within the heat exchanger as can be seen in temperature distributions presented in Figures 9 and 10 for cases 1 and 7, respectively. The hottest region of the cold fluid zone was located between the separation element in the S-shape for configuration II and at the

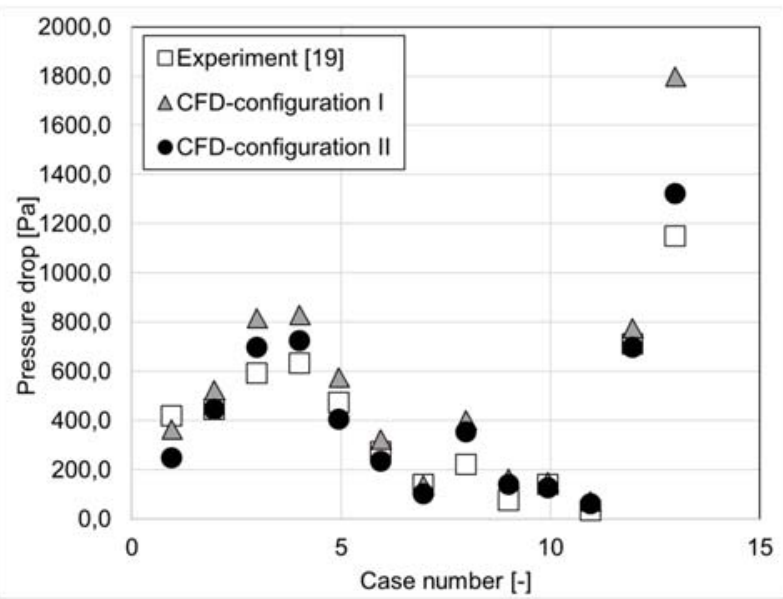

(a) upper part of the wall close to the cold side outlet for configuration I, while larger temperature changes for the hot fluid zone were achieved in both heat exchanger configurations in the inlet and split fluid flow zones. In those zones, recirculation and high pressure spots can also be seen. This behaviour resulted from the plates

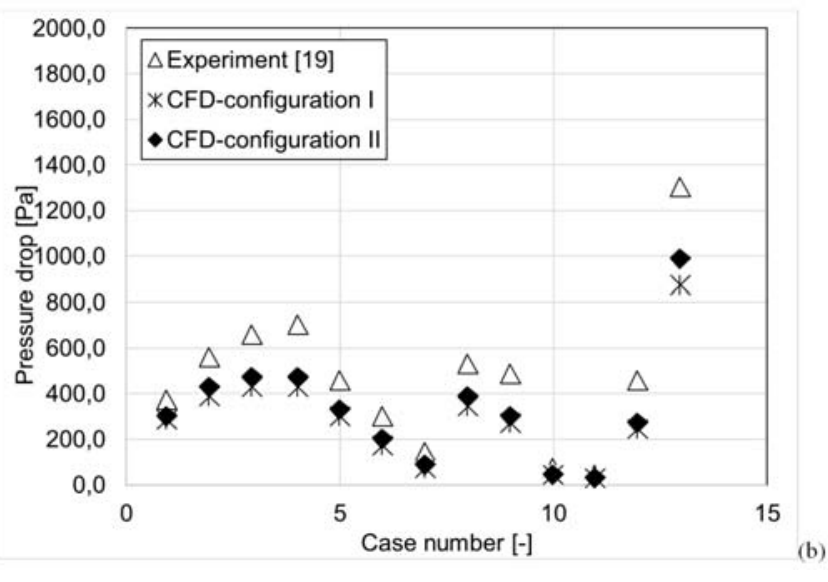

Figure 6. Comparison of the CFD predicted and experimental values of friction factor for both configurations I and II of the plate heat exchanger: (a) hot fluid flow, (b) cold fluid flow 

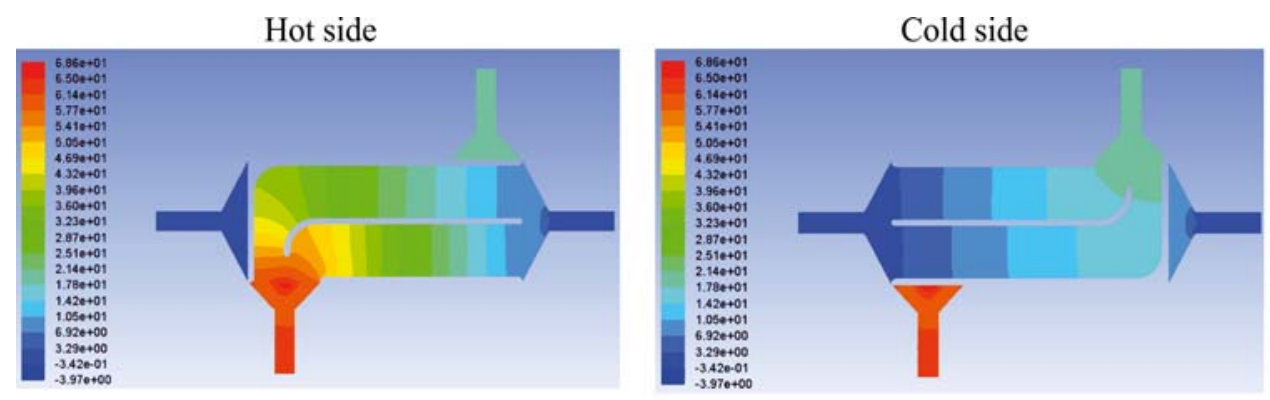

(a)
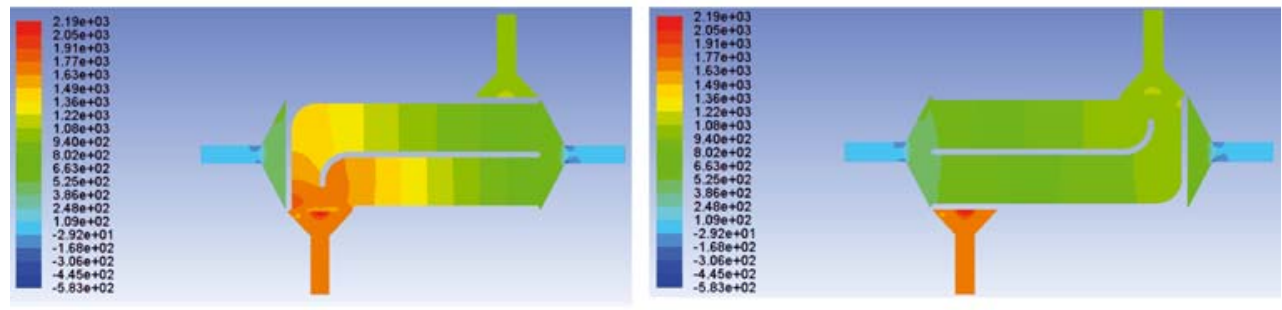

(b)

Figure 7. Pressure distributions $[\mathrm{Pa}]$ in the heat exchanger configuration I for: (a) case 11, (b) case 13
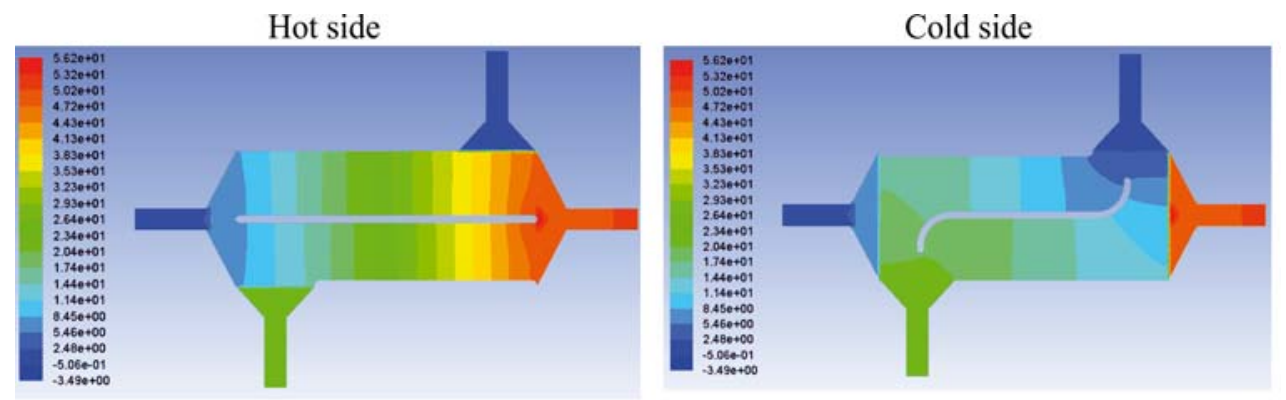

(a)
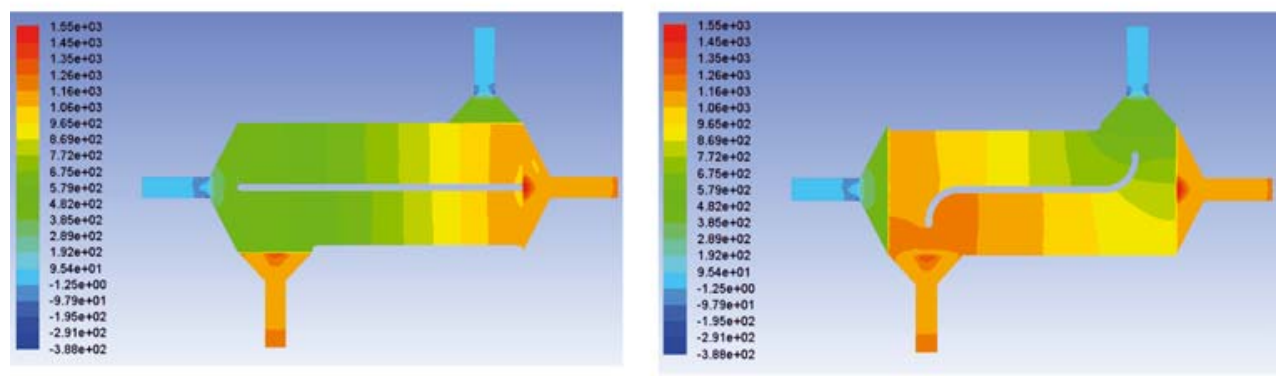

(b)

Figure 8. Pressure distributions $[\mathrm{Pa}]$ in the heat exchanger configuration II for: (a) case 11, (b) case 13

arrangement. It seems, on the one side, that the applied fluid flow division allows to improve mixing and in consequence leads to an increase of the heat transfer. On the other side, local hot spots can be observed, which can cause material problems and should be avoided due to safety reasons.

Analysis of the simulated temperatures at the outlets from the heat exchanger (configuration I) revealed that a quite good agreement was obtained between the CFD results and the measured ones by ${ }^{19}$, as it can be seen from Figure 11. The maximum deviation between the simulation and experimental values of temperature for hot fluid was equal to $17 \%$, while for the cold fluid it was $13 \%$. Therefore, it can be assumed the CFD temperature distributions of configuration I were close to the real ones. As indicated in Figure 11 for the second configuration of the plate heat exchanger, the agreement between the CFD and experimental results was even better. The maximum deviation between simulation and experimental values was equal to $15 \%$ and $12 \%$ for the cold and hot fluids, respectively. In addition, it should be underlined that application of the second configuration of the plate heat exchanger allows decreasing the hot fluid temperature at the outlet in the operating fluid flow rate and results in heat transfer enhancement.

\section{CONCLUSIONS}

Comparison of two heat exchanger configurations with different plates' arrangement showed that the second configuration allows to obtain lower outlet temperature for the hot fluid flow. In all considered CFD cases, an increased Reynolds number caused a decrease of the friction factor and increase in the pressure drop. A higher pressure drop for the hot fluid of $26 \%$ was noticed for the configuration I of the plate heat exchanger in com- 
Hot side
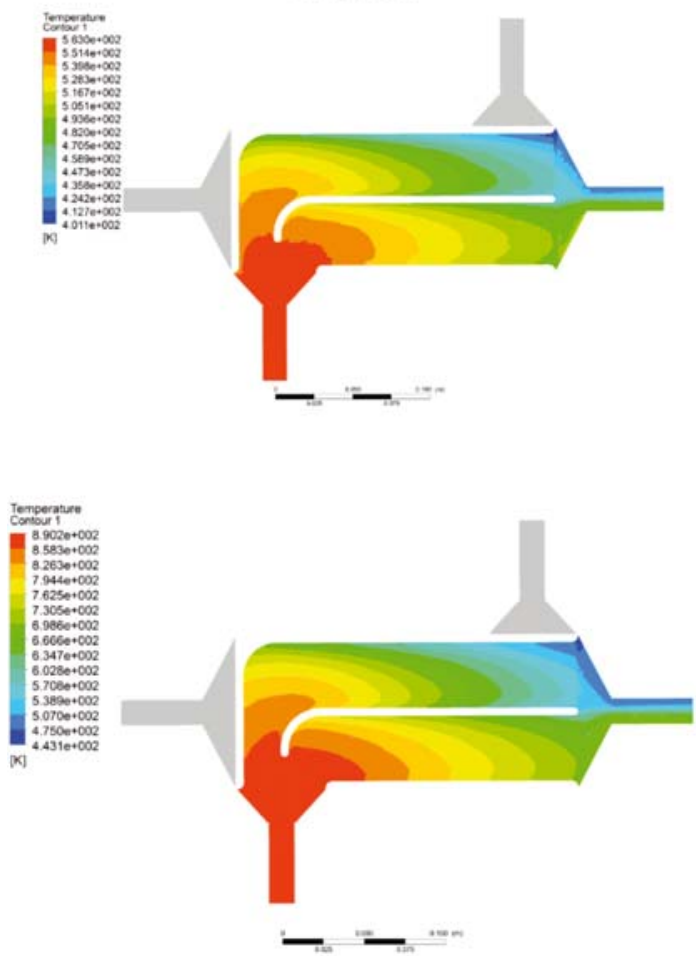

Cold side

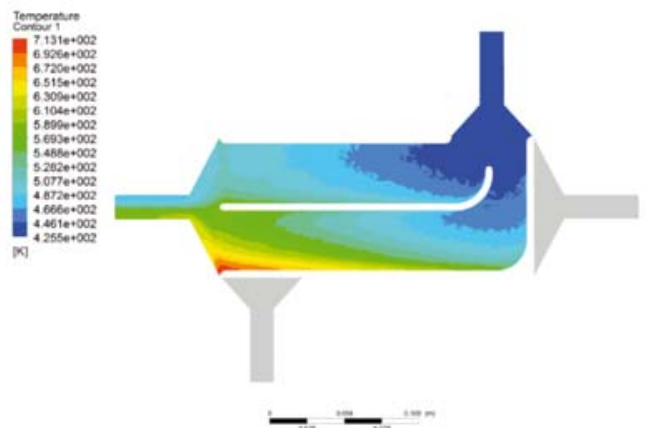

(a)

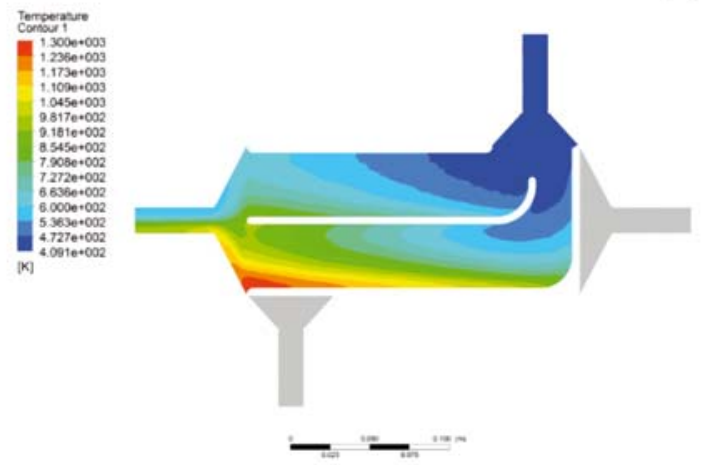

(b)

Figure 9. Temperature distributions $[\mathrm{K}]$ in the heat exchanger configuration I for: (a) case 1, (b) case 7

Hot side

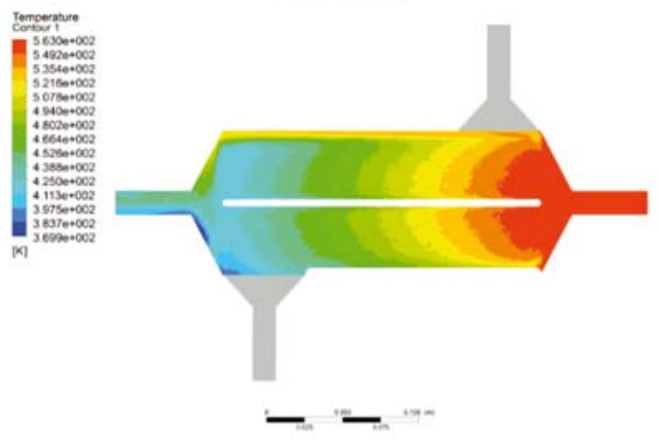

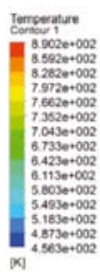
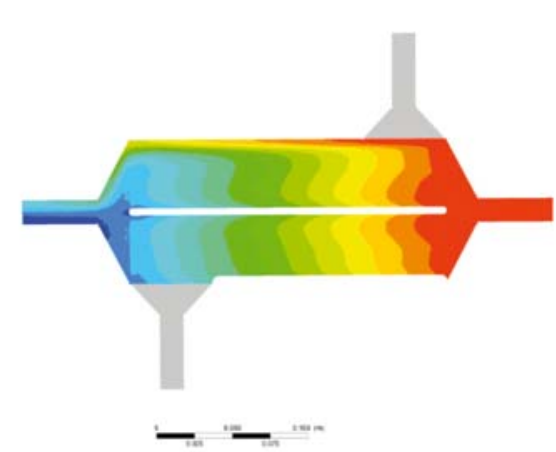

Cold side

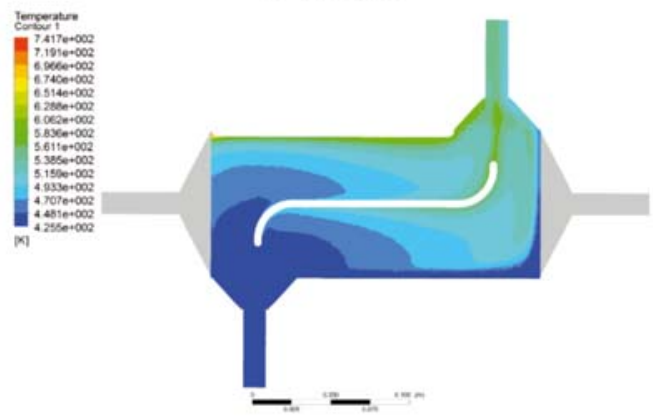

(a)

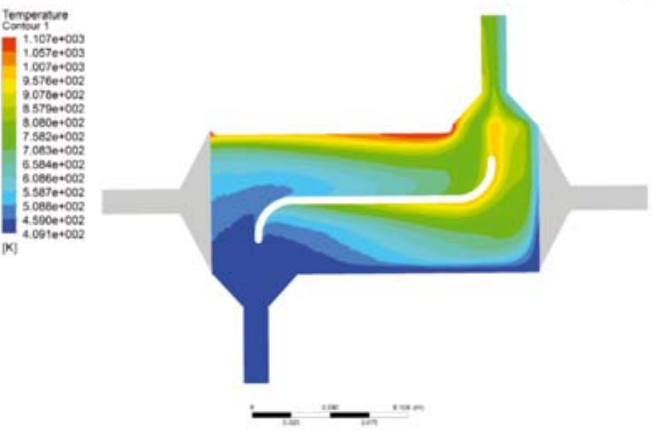

(b)

Figure 10. Temperature distributions $\lfloor K\rfloor$ in the heat exchanger configuration II for: (a) case 1, (b) case 7

parison to configuration II, indicating higher turbulence intensity. However, it seems that the critical impact on the heat transfer efficiency in the plate heat exchanger has the cold fluid distributions. The pressure drop for the cold fluid was higher of about $13 \%$ in configuration II than in I. Thus, the CFD results showed a significant importance of fluid flow nonuniformity on the heat exchanger efficiency. Moreover, the present study with respect to flow maldistribution (dead fluid zones), demonstrates that 3D CFD simulations are a useful tool for analyzing, designing and optimizing heat exchanger design. The results of this study can be also helpful in further optimization of heat exchanger configuration in order to minimize flow maldistribution. 

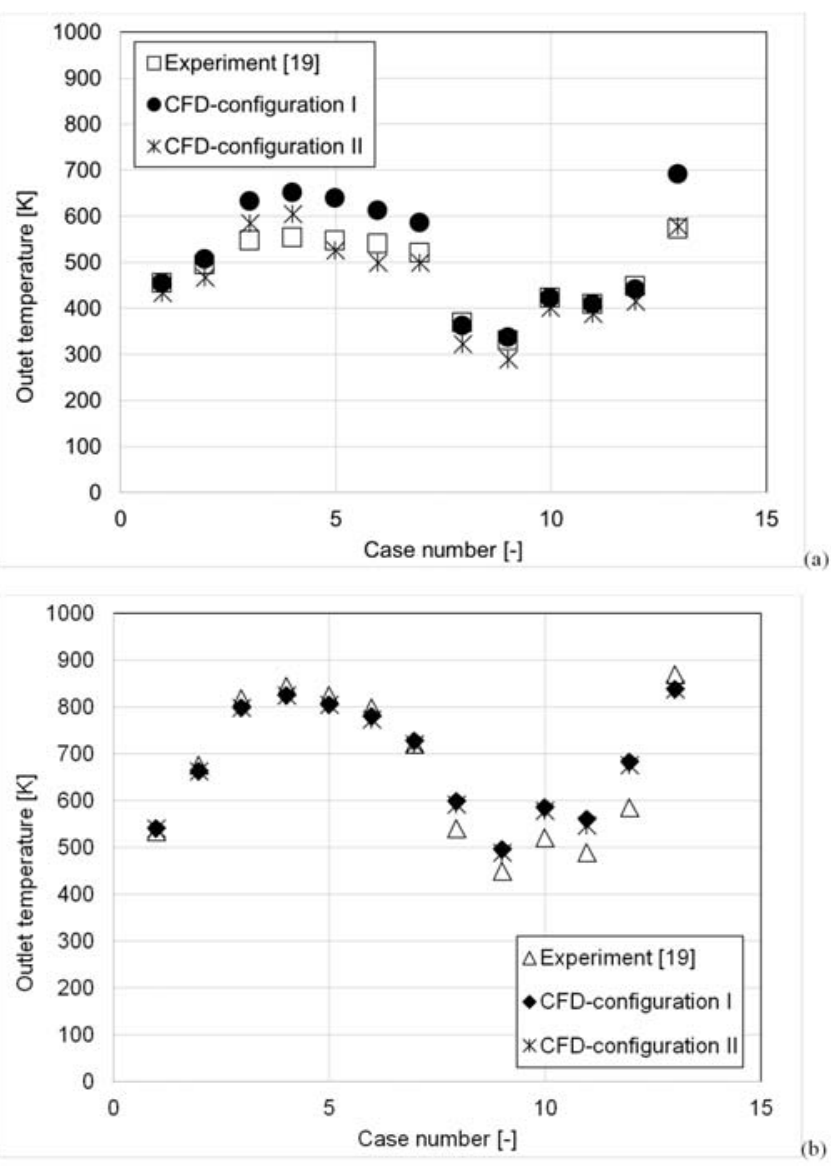

Figure 11. Comparison of the outlet temperature from CFD and experiments ${ }^{19}$ values for the plate heat exchanger with configurations I and II for hot (a) and cold (b) fluids

\section{NOMENCLATURE}

$C_{p} \quad-$ average specific heat $\left[\mathrm{Jkg}^{-1} \mathrm{~K}^{-1}\right]$

$C_{1 \varepsilon} \quad$ - adjustable constant [-]

$C_{2 \varepsilon} \quad$ - adjustable constant [-]

$C_{\mu} \quad$ - adjustable constant [-]

$D_{h} \quad$ - hydraulic diameter of channel [m]

$f \quad-$ friction factor [-]

$g \quad-$ acceleration due to gravity $\left[\mathrm{ms}^{-2}\right]$

I $\quad$ - unit tensor [-]

$K \quad-$ turbulent kinetic energy $\left[\mathrm{m}^{2} \mathrm{~s}^{-2}\right]$

$k \quad-$ thermal conductivity $\left[\mathrm{Wm}^{-1} \mathrm{~K}^{-1}\right]$

$L \quad$ - length of the channel [m]

$N \quad$ - mass flow rate $\left[\mathrm{kg} \mathrm{s}^{-1}\right]$

$p \quad-$ pressure $[\mathrm{Pa}]$

Re - Reynolds number, $\operatorname{Re}=\frac{v D_{h} \rho}{\mu}[-]$

$R_{\varepsilon} \quad$ - additional term in RNG model [-]

$S \quad$ - modulus of the mean rate of strain tensor $\mathrm{Pa}]$

$T \quad$ - temperature $[\mathrm{K}]$

$\bar{v} \quad-$ velocity $\left[\mathrm{ms}^{-1}\right]$

\section{Greek symbols}

$\beta \quad$ - adjustable constant [-]

$\varepsilon \quad-$ dissipation rate of kinetic turbulence energy $\left[\mathrm{m}^{2} \mathrm{~s}^{-3}\right]$

$\eta$ - ratio of the mean flow to turbulent time scale [-]

$\eta_{0} \quad$ - adjustable constant [-]

$\lambda \quad-$ thermal conductivity $\left[\mathrm{Wm}^{-1} \mathrm{~K}^{-1}\right]$ $\mu \quad-$ molecular viscosity [Pas]

$\mu_{t} \quad-$ turbulent eddy viscosity [Pas]

$\rho \quad$ - fluid density $\left[\mathrm{kg} \mathrm{m}^{-3}\right]$

$\sigma_{k} \quad-$ turbulent Prandtl number for k [-]

$\sigma_{\varepsilon} \quad-$ turbulent Prandtl number for $\varepsilon[-]$

$\bar{\tau} \quad-$ stress tensor $[\mathrm{Pa}]$

$\Delta P \quad-$ pressure loss $\left[\mathrm{Nm}^{-2}\right]$

\section{ACKNOWLEDGEMENTS}

The research programme leading to these results received funding from the European Union's Seventh Framework Programme (FP7/2007-2013) for the Fuel Cells and Hydrogen Joint Undertaking (FCH JU) under grant agreement $\mathrm{n}^{\mathrm{o}}$ [621213]. Information contained in the paper reflects only view of the authors. The $\mathrm{FCH}$ $\mathrm{JU}$ and the Union are not liable for any use that may be made of the information contained therein. Acknowledgments are due to the partners of STAGE-SOFC project.

The work was also financed from the Polish research funds awarded for the project No. 3126/7.PR/2014/2 of international cooperation within STAGE-SOFC in years 2014-2017.

\section{LITERATURE CITED}

1. Khan, T.S., Khan, M.S., Chyu, M.C. \& Ayub, Z.H. (2010). Experimental investigation of single phase convective heat transfer coefficient in a corrugated plate heat exchanger for multiple plate configurations, Appl. Ther. Engine. 30, 1058-1065. DOI: 10.1016/j.applthermaleng.2010.01.021.

2. Gherasim, I., Taws, M., Galanis, N. \& Nguyen, C.T. (2011). Heat transfer and fluid flow in a plate heat exchanger part I. Experimental investigation. Inter. J. Ther. Sci. 50, 1492-1498. DOI: 10.1016/j.ijthermalsci.2011.03.018.

3. Kraus, A.D., Aziz, A. \& Welty, J. (2007). Extended surface heat transfer. John Wiley \& Sons, Inc. DOI: 10.1002/978047017582.

4. Abu-Khader, M.M. (2012). Plate heat exchangers: recent advances. Renew. Sustain. Ener. Rev. 16, 1883-1891. DOI: 10.1016/j.rser.2012.01.009.

5. Arie, M.A., Shooshtari, A.H., Dessiatoun, S.V., Al-Hajri, E. \& Ohadi, M.M. (2015). Numerical modeling and thermal optimization of a single phase flow manifold microchannel plate heat exchanger, Inter. J. Heat Mass Trans. 81, 478-489. DOI: 10.1016/j.ijheatmasstransfer.2014.10.022.

6. Goodarzi, M. \& Nouri, E. (2016). A new double-pass parallel-plate heat exchanger with better wall temperature uniformity under uniform heat flux. Inter. J. Ther. Sci. 102, 137-144. DOI: 10.1016/j.ijthermalsci.2015.11.012.

7. Kim, G.W., Lim, H.M. \& Rhee, G.H. (2016). Numerical studies of heat transfer enhancement by cross-cut flow control in wavy fin heat exchanger, Inter. J. Heat Mass Trans. 96, 110-117. DOI: 10.1016/j.ijheatmasstransfer.2016.01.023.

8. Yaici, W., Ghorab, M. \& Entchev, E. (2014). 3D CFD analysis of the effect of inlet air flow maldistribution on the fluid flow and heat transfer performances of plate-fin-andtube laminar, heat exchangers, Inter. J. Heat Mass Trans. 74, 490-500. DOI: 10.1016/j.ijheatmasstransfer.2014.03.034.

9. Vafajoo, L., Moradifar, K., Hosseini, S.M. \& Salman, B.H. (2016). Mathematical modelling of turbulent flow for flue gas-air Chevron type plate heat exchangers. Inter. J. Heat Mass Trans. 97, 596-602. DOI: 10.1016/j.ijheatmasstransfer.2016.02.035.

10. Shah, R.K. \& Sekulic, D.P. (2007). Fundamentals of heat exchanger design, John \& Sons, Inc., ISBN: 0-471-32171-0.

11. Wakui, T. \& Yokoyama, R. (2008). Online model based performance monitoring of a shell and tube type heat exchanger 
using steam and water. Ener. Conv. Manage. 49, 2669-2677. DOI: 10.1016/j.enconman.2008.04.009.

12. Tao, W.Q., Cheng, Y.P. \& Lee, T.S. (2007). 3D numerical simulation on fluid flow and heat transfer characteristics in multistage heat exchanger with slit fins. Heat Mass Trans. 44, 125-136. DOI: 10.1007-s00231-0060-0227-2.

13. Luan, Z.J., Zhang, G.M., Tian, M.Ch. \& Fan, M.X. (2008). Flow resistance and heat transfer characteristics of a new type plate heat exchanger. J. Hydro. 20, 4, 524-529.

14. Giurgiu, O., Plesa, A. \& Socaciu, L. (2016). Plate heat exchangers - flow analysis through mini channels. Ener. Proc. 85, 244-251. DOI: 10.1016/j.egypro.2015.12.236.

15. Andhare, R.S., Shooshtari, A., Dessiatoun, S.V. \& Ohadi, M.M. (2016). Heat transfer and pressure drop characteristics of a flat plate manifold microchannel heat exchanger in counter flow configuration. Appl. Ther. Engine. 96, 178-189. DOI: 10.10116/j.aapthermaleng.2015.10.133.

16. Rios-Iribe, E.Y., Cervantes-Gaxiola, M.E., Rubio-Castro, E. \& Hernadez-Calderon, O.M. (2016). Heat transfer analysis of a non-Newtonian fluid flowing through a plate heat exchanger using CFD. Appl. Ther. Engine. DOI: 10.1016/j.applthermaleng.2016.02.094.

17. Dvorak, V. \& Vit, T. (2015). Numerical investigation of counter flow plate heat exchanger. Ener. Proc. 83, 341-349. DOI: 10.1016/j.egypro.2015.12.188.

18. ANSYS Inc. Fluent 15.0, User's guide, ANSYS Inc. Houston, TX, 2015.

19. Internal report from sunfire, 2015.

20. Bhatti, M.S. \& Shah, R.K. (1987). Turbulent and transition flow convective heat transfer in duct, chapter 4 in Handbook of Single phase convective heat transfer, S. Kakac, R.K. Shah, W. Aung, John Wiley \& Sons, New York, 95-101.

21. Shah, R.K. (2007). Compact heat exchangers - recuperators and regenerators, chapter 13 in Handbook of Energy efficiency and renewable energy, F. Kreith, D.Y. Goswami, $7^{\text {th }}$ May 2007, CRC Press, ISBN: 9780849317309, 13-1-13-72.

22. Pianko-Oprych, P., Kasilova, E. \& Jaworski, Z. (2014). Quantification of the radiative and convective heat transfer processes and their effect on mSOFC by CFD modelling. Pol. J. Chem. Technol. 86, 7, 1029-1043. DOI: 10.2478/pjct-2014-0029.

23. Launder, B.E. \& Spalding, D.B. (1972). Lectures in Mathematical Models of Turbulence, Academic Press, London, UK. 